\title{
Etiology and Management of Behavioral Disorder in Adults With Intellectual and Developmental Disabilities
}

\author{
Govind H. Kallumkal ${ }^{1}$, Rafik Jacob ${ }^{2}$, Linda Edwards ${ }^{2}$ \\ 1. Internal Medicine, University of Florida College of Medicine, Gainesville, USA 2. Internal Medicine, University of \\ Florida College of Medicine - Jacksonville, Jacksonville, USA
}

Corresponding author: Rafik Jacob, rafik.jacob@jax.ufl.edu

\begin{abstract}
Intellectual disability (ID) encompasses a wide variety of disorders that can severely affect an individual's cognitive, social, emotional, and physical development, even when identified early in life. Initially, individuals with such disorders had shorter life expectancies. However, medical advances have increased the life expectancy of individuals with ID similar to that of the general population. More attention must be paid to manage diseases affecting the intellectually disabled elderly, such as diabetes, cardiovascular disease, chronic constipation, and behavioral disorders.
\end{abstract}

Categories: Family/General Practice, Psychiatry, Other

Keywords: intellectual and developmental disabilities, antipsychotics, behavioral modification, behavioral disorder

\section{Introduction And Background}

An issue of particular significance for caretakers and physicians of individuals with intellectual disability (ID) is behavioral disorder/disruption. Ranging from mild repetitive movements to actions injurious to caretakers and self, behavioral disorders can be challenging for caretakers. Often, the etiology of these disruptions is secondary to alterations in the patient's environment and can be caused by physical and psychiatric health issues. The patient's communication difficulties can make the identification of the etiology of the behavioral disorder challenging. Treatment is multidisciplinary and requires the use of therapy and antipsychotics.

\section{Review}

\section{Etiology of behavioral disorder in ID}

Behavioral disruption ranges from minor stereotypical actions, such as body rocking, hand wringing, and crossing of legs, to behavior injurious to self, others, and property [1]. The Royal College of Psychiatrists has defined behavioral disruption as "it is of such intensity, frequency, or duration, as to threaten the quality of life and/or the physical safety of the individual or others, and is likely to lead to responses that are restrictive, aversive, or result in exclusion." The prevalence of behavioral disorders ranges between $10 \%$ and $55 \%[2,3]$. It is estimated that dangerous, self-injurious actions occur at a rate of $4-5 \%$ in children [4]. Additionally, the severity of ID plays a significant role in the severity of behavioral disruption. The worse the disability, the worse the disruption [5].

(c) Copyright 2021 Kallumkal et al. This is an open access article distributed under the terms of the Creative Commons Attribution License CC-BY 4.0., which permits unrestricted use, distribution, and reproduction in any medium, provided the original author and source are credited.
The surroundings and environment often play a role in behavioral disruption. In circumstances where the patients feel uncomfortable, he/she is more likely to lash out in frustration/discomfort [4]. For instance, if a physician's office represents a disturbing environment for the patient, they may respond with disruptive behavior. These behaviors may also be secondary to frustration with the caregiver demands [6]. Certain patients may respond poorly if they are not agreeable to caretaker requests to perform a particular exercise or eat a certain food. Depending on the severity of the reaction, caregivers may attempt to placate the patients to stop the behavior. They often do so by continuing to allow performance of actions that are not desired or by supplying treats or toys. However, placation can create a positive feedback response, which further reinforces poor behavior [7]. As patients begin to associate desirable consequences to their problem behavior, they are further empowered in their actions.

Anxiety and other comorbid psychiatric disorders are a significant concern when caring for individuals with ID [8]. A total of $55.3 \%$ of children with non-specified developmental disorders and $26.8 \%$ of adults with ID show symptoms of anxiety. Similarly, $4.4 \%$ of individuals with ID exhibit depression [9]. Comorbid disorders, which are difficult to diagnose in these populations, can increase feelings of discomfort, further contributing to behavioral disruption. Psychiatric issues are difficult to diagnose in individuals who cannot communicate adequately. This can often lead to feelings of increased frustration by the patients and can be an added reason for disruptive behavior. 
Physical discomfort can also cause behavioral disruption, as seen in emotional and psychiatric discomfort [10]. The reduced capability of self-expression often prolongs discomfort and raises the frustration associated with it. One prevalent example is constipation. Up to 75\% of individuals with ID experience chronic constipation [10-11], which is associated with increased behavioral disruption [12]. Other chronic issues, such as gastroesophageal reflux disease (GERD), occur in 48\% of individuals with ID [13]. Common chronic conditions, including allergies [14] and otitis media [15], can also cause problem behavior [16]. Any medical issue that causes significant discomfort to patients can lead to problematic behavior. Dysmenorrhea is twice as common in individuals with ID [17]. If behavioral disruption is associated with dysmenorrhea, the problematic behavior is also cyclic, resolving with the end of menstruation [18]. Other issues, such as undiagnosed physical trauma, seizure disorder, and vision and hearing impairment, can be other stimuli for problematic behavior [10].

Behavioral disorders may also be secondary to physical and sexual abuse. Individuals with ID are abused at significantly higher rates than the general population. Up to $34 \%$ of individuals with ID experience sexual abuse [19]. Furthermore, these individuals are more likely to experience issues, such as depression or anxiety, and are more likely to participate in self-injury or stereotypy [20-22].

\section{Diagnosis of behavioral disorders in individuals with ID}

The diagnosis of behavioral disruption and its etiology begins with a thorough history, including baseline behavior, identification of events that initiate problem behavior, and experiences that reinforce or inhibit problem behavior [23]. Particular focus should also be given to understanding the caretaker's response to disruptive behavior. Because patients may have difficulty in expression and communication, histories must often be taken from caregivers [24]. A significant understanding of behavioral disruption may be obtained through rating scales, interviews, and observations in natural settings.

In case of behavioral disorder secondary to physical discomfort, a thorough history of events before and after the behavioral changes, and an adequate physical examination and imaging, may be warranted [10]. For example, if a behavioral change is secondary to abdominal discomfort from a history of constipation, a thorough abdominal and rectal examination along with radiography may be warranted. Furthermore, patients' actions can help identify the nature of their pain. Ear poking or pulling may occur concurrently with otitis media [25], hand mouthing with GERD [26], and headbanging with allergies [27].

\section{Management of behavioral disorders in individuals with ID}

Therapy and behavioral modifications are the foundations of behavioral disruption management. Therapy should be attempted before the use of antipsychotics when managing behavioral disruptions. The primary modality of therapy is function-based treatment [28]. The goal of the specific therapy is to reinforce or support appropriate alternative behaviors while negatively reinforcing bad behavior and reducing its frequency. Early therapy initiation is more likely to eliminate bad behavior [20]. Appropriate behavior is more likely to be preserved when caretakers maintain adequate reinforcement [7]. Resolving medical and metabolic contributions is warranted in conjunction with behavioral therapy. Using both modalities of care will allow the existing stimulus to be resolved, while equipping patients and caretakers with better coping techniques.

Antipsychotics may be necessary when therapy cannot eliminate behavioral disruption adequately or when behavior poses a risk to patients or their caregivers [29]. Medications should be used to decrease emotional creativity, irritability, impulsivity, and work synergistically with therapy. Among all patients with ID, approximately 30\% regularly use antipsychotics [30] compared to $48 \%$ of patients with ID who exhibit significant behavioral problems [31]. The two most frequently used medications are risperidone and aripiprazole, both are administered in a dose lower than that in schizophrenia treatment [32]. These medications are commonly used for the management of ID. Efficacy is unclear when used in managing problem behavior. Previous studies show mixed efficacy when compared to placebo [33-36]. However, treatment is significantly more effective when used for patients with comorbid psychiatric disorders [32].

Antipsychotics medications should be administered with caution because of extensive side effects, particularly in individuals with ID [37]. In case of patients on risperidone, physicians must pay close attention to extrapyramidal symptoms (occurring in $37.6 \%$ of users) such as tremor, dystonia, and akathisia. Metabolic changes, such as hyperprolactinemia (occurring in $87.2 \%$ of users), weight gain, hyperglycemia, hyperlipidemia, and other effects such as constipation and amenorrhea, should be closely monitored [38]. Aripiprazole's side effect profile has some similarities to risperidone, including, but not limited to, restlessness/akathisia, somnolence, and nausea in a dose-dependent manner [39]. The long-term metabolic side effects of these medications should be considered owing to the sedentary nature of many individuals with IDs. Hyperprolactinemia can lead to hypogonadism and osteoporosis, while hyperlipidemia and hyperglycemia can lead to an increased cardiovascular risk [40].

When atypical antipsychotics are initiated, baseline vital signs, such as blood pressure and waist circumference, should be obtained in addition to laboratory findings, such as fasting lipids, glucose, thyroxine, and thyroid-stimulating hormone levels. Plasma drug levels need not be monitored [41]. However, 
patients should be monitored monthly to assess body weight, with laboratory findings being evaluated every three months. If laboratory findings and vital signs remain stable, follow-up may be less frequent [42]. Once behavioral issues are appropriately controlled, medications should be weaned to their smallest effective dose [43].

\section{Conclusions}

With the improvement in medical care, the life expectancy of patients with ID has increased, and their care has become similar to that of the general aging population. Problematic or disruptive behavior is one of the most common and challenging issues faced by physicians and caretakers. Actions range from benign, such as ear tugging, to behaviors that are dangerous to patients and caretakers. Inappropriate coping mechanisms cause actions in response to psychiatric and medical distress, and environmental change. Diagnosis requires thorough history taking, appropriate physical examinations, and imaging when required. Treatment focuses on resolving the distressing stimulus while reinforcing proper coping techniques. Antipsychotics, such as risperidone and aripiprazole, can be used in circumstances where problem behavior is refractory to therapy. Patients managed with such medications should be monitored regularly for possible side effects, particularly because of the high-risk status of individuals with ID.

\section{Additional Information \\ Disclosures}

Conflicts of interest: In compliance with the ICMJE uniform disclosure form, all authors declare the following: Payment/services info: All authors have declared that no financial support was received from any organization for the submitted work. Financial relationships: All authors have declared that they have no financial relationships at present or within the previous three years with any organizations that might have an interest in the submitted work. Other relationships: All authors have declared that there are no other relationships or activities that could appear to have influenced the submitted work.

\section{References}

1. Kerr M, Gil-Nagel A, Glynn M, Mula M, Thompson R, Zuberi SM: Treatment of behavioral problems in intellectually disabled adult patients with epilepsy. Epilepsia. 2013, 54:34-40. 10.1111/epi.12103

2. Lowe K, Allen D, Jones E, Brophy S, Moore K, James W: Challenging behaviours: prevalence and topographies. J Intellect Disabil Res. 2007, 51:625-36. 10.1111/j.1365-2788.2006.00948.x

3. Cooper SA, Smiley E, Morrison J, Williamson A, Allan L: Mental ill-health in adults with intellectual disabilities: prevalence and associated factors. Br J Psychiatry. 2007, 190:27-35. 10.1192/bjp.bp.106.022483

4. Ruddick L, Davies L, Bacarese-Hamilton M, Oliver C: Self-injurious, aggressive and destructive behaviour in children with severe intellectual disability: prevalence, service need and service receipt in the UK. Res Dev Disabil. 2015, 45-46:307-15. 10.1016/j.ridd.2015.07.019

5. Lakhan R, Kishore MT: Behaviour problems in children with intellectual disabilities in a resource-poor setting in India - Part 1: Association with age, sex, severity of intellectual disabilities and IQ. J Appl Res Intellect Disabil. 2018, 31:43-50. 10.1111/jar.12278

6. Furniss F, Biswas AB: Recent research on aetiology, development and phenomenology of self-injurious behaviour in people with intellectual disabilities: a systematic review and implications for treatment. J Intellect Disabil Res. 2012, 56:453-75. 10.1111/j.1365-2788.2012.01534.x

7. Stocco CS, Thompson RH: Contingency analysis of caregiver behavior: Implications for parent training and future directions. J Appl Behav Anal. 2015, 48:417-35. 10.1002/jaba.206

8. Davis E, Saeed SA, Antonacci DJ: Anxiety disorders in persons with developmental disabilities: empirically informed diagnosis and treatment. Reviews literature on anxiety disorders in DD population with practical take-home messages for the clinician. Psychiatr Q. 2008, 79:249-63. 10.1007/s11126-008-9081-3

9. Lunsky Y, Palucka AM: Depression in intellectual disability. Curr Opin Psychiatry. 2004, 17:359-63.

10. May ME, Kennedy $\mathrm{CH}$ : Health and problem behavior among people with intellectual disabilities . Behav Anal Pract. 2010, 3:4-12. 10.1007/BF03391759

11. Böhmer CJ, Taminiau JA, Klinkenberg-Knol EC, Meuwissen SG: The prevalence of constipation in institutionalized people with intellectual disability. J Intellect Disabil Res. 2001, 45:212-8. 10.1046/j.13652788.2001.00300.x

12. Christensen TJ, Ringdahl JE, Bosch JJ, Falcomata TS, Luke JR, Andelman MS: Constipation associated with self-injurious and aggressive behavior exhibited by a child diagnosed with autism. Educ Treat Children. 2009, 32:89-103. 10.1353/etc.0.0041

13. Böhmer CJ, Niezen-de Boer MC, Klinkenberg-Knol EC, Devillé WL, Nadorp JH, Meuwissen SG: The prevalence of gastroesophageal reflux disease in institutionalized intellectually disabled individuals. Am J Gastroenterol. 1999, 94:804-10. 10.1111/j.1572-0241.1999.00854.x

14. Shott SR: Down syndrome: common otolaryngologic manifestations. Am J Med Genet C Semin Med Genet. 2006, 142:131-40. 10.1002/ajmg.c.30095

15. Mitchell RB, Call E, Kelly J: Ear, nose and throat disorders in children with Down syndrome . Laryngoscope. 2003, 113:259-63. 10.1097/00005537-200302000-00012

16. Bramble D: Two cases of severe head-banging parasomnias in peripubertal males resulting from otitis media in toddlerhood. Child Care Health Dev. 1995, 21:247-53. 10.1111/j.1365-2214.1995.tb00755.x

17. Osuga Y, Hayashi K, Kobayashi Y, et al.: Dysmenorrhea in Japanese women. Int J Gynaecol Obstet. 2005, 88:82-3. 10.1016/j.ijgo.2004.09.004

18. Quint EH, Elkins TE, Sorg CA, Kope S: The treatment of cyclical behavioral changes in women with mental disabilities. J Pediatr Adolesc Gynecol. 1999, 12:139-42. 10.1016/s1038-3188(99)00006-6 
19. Smit MJ, Scheffers M, Emck C, van Busschbach JT, Beek PJ: Clinical characteristics of individuals with intellectual disability who have experienced sexual abuse. An overview of the literature. Res Dev Disabil. 2019, 95:103513. 10.1016/j.ridd.2019.103513

20. Maniglio R: The impact of child sexual abuse on health: a systematic review of reviews . Clin Psychol Rev. 2009, 29:647-57. 10.1016/j.cpr.2009.08.003

21. Sequeira H, Howlin P, Hollins S: Psychological disturbance associated with sexual abuse in people with learning disabilities. Case-control study. Br J Psychiatry. 2003, 183:451-6. 10.1192/bjp.183.5.451

22. Mansell S, Sobsey D, Moskal R: Clinical findings among sexually abused children with and without developmental disabilities. Ment Retard. 1998, 36:12-22. 10.1352/00476765(1998)036<0012:CFASAC>2.0.CO;2

23. Kurtz PF, Leoni M, Hagopian LP: Behavioral approaches to assessment and early intervention for severe problem behavior in intellectual and developmental disabilities. Pediatr Clin North Am. 2020, 67:499-511. 10.1016/j.pcl.2020.02.005

24. Smith M, Manduchi B, Burke É, Carroll R, McCallion P, McCarron M: Communication difficulties in adults with intellectual disability: results from a national cross-sectional study. Res Dev Disabil. 2020, 97:103557. 10.1016/j.ridd.2019.103557

25. O'Reilly MF: Functional analysis of episodic self-injury correlated with recurrent otitis media . J Appl Behav Anal. 1997, 30:165-7. 10.1901/jaba.1997.30-165

26. Swender SL, Matson JL, Mayville SB, Gonzalez ML, McDowell D: A functional assessment of handmouthing among persons with severe and profound intellectual disability. J Intellect Dev Disabil. 2006, 31:95-100. 10.1080/13668250600710880

27. Kennedy CH, Meyer KA: Sleep deprivation, allergy symptoms, and negatively reinforced problem behavior . J Appl Behav Anal. 1996, 29:133-5. 10.1901/jaba.1996.29-133

28. Beavers GA, Iwata BA, Lerman DC: Thirty years of research on the functional analysis of problem behavior . J Appl Behav Anal. 2013, 46:1-21. 10.1002/jaba.30

29. La Malfa G, Lassi S, Bertelli M, Castellani A: Reviewing the use of antipsychotic drugs in people with intellectual disability. Hum Psychopharmacol. 2006, 21:73-89. 10.1002/hup.748

30. Branford D: A study of the prescribing for people with learning disabilities living in the community and in National Health Service care. J Intellect Disabil Res. 1994, 38:577-86. 10.1111/j.1365-2788.1994.tb00459.x

31. Kiernan C, Reeves D, Alborz A: The use of anti-psychotic drugs with adults with learning disabilities and challenging behaviour. J Intellect Disabil Res. 1995, 39:263-74. 10.1111/j.1365-2788.1995.tb00518.x

32. O'Dwyer C, McCallion P, Henman M, et al.: Prevalence and patterns of antipsychotic use and their associations with mental health and problem behaviours among older adults with intellectual disabilities. J Appl Res Intellect Disabil. 2019, 32:981-93. 10.1111/jar.12591

33. Vanden Borre R, Vermote R, Buttiëns M, et al.: Risperidone as add-on therapy in behavioural disturbances in mental retardation: a double-blind placebo-controlled cross-over study. Acta Psychiatr Scand. 1993, 87:167-71. 10.1111/j.1600-0447.1993.tb03350.x

34. Gagiano C, Read S, Thorpe L, Eerdekens M, Van Hove I: Short- and long-term efficacy and safety of risperidone in adults with disruptive behavior disorders. Psychopharmacology (Berl). 2005, 179:629-36. 10.1007/s00213-004-2093-2

35. Tyrer P, Oliver-Africano PC, Ahmed Z, et al.: Risperidone, haloperidol, and placebo in the treatment of aggressive challenging behaviour in patients with intellectual disability: a randomised controlled trial. Lancet. 2008, 371:57-63. 10.1016/S0140-6736(08)60072-0

36. Deb S: Psychopharmacology. Handbook of Evidence-Based Practices in Intellectual and Developmental Disabilities. Singh N (ed): Springer International Publishing, Cham; 2016. 347-81.

37. Sheehan R, Horsfall L, Strydom A, Osborn D, Walters K, Hassiotis A: Movement side effects of antipsychotic drugs in adults with and without intellectual disability: UK population-based cohort study. BMJ Open. 2017, 7:017406. 10.1136/bmjopen-2017-017406

38. Alladi CG, Mohan A, Shewade DG, Rajkumar RP, Adithan S, Subramanian K: Risperidone-induced adverse drug reactions and role of DRD2 (-141 C Ins/Del) and 5HTR2C (-759 C>T) genetic polymorphisms in patients with schizophrenia. J Pharmacol Pharmacother. 2017, 8:28-32. 10.4103/jpp.JPP_197_16

39. Fleischhacker WW: Aripiprazole. Expert Opin Pharmacother. 2005, 6:2091-101. 10.1517/14656566.6.12.2091

40. Frighi V, Stephenson MT, Morovat A, et al.: Safety of antipsychotics in people with intellectual disability . Br J Psychiatry. 2011, 199:289-95. 10.1192/bjp.bp.110.085670

41. Mauri MC, Paletta S, Maffini M, Colasanti A, Dragogna F, Di Pace C, Altamura AC: Clinical pharmacology of atypical antipsychotics: an update. EXCLI J. 2014, 13:1163-91.

42. American Diabetes Association,, American Psychiatric Association, American Association of Clinical Endocrinologists, and North American Association for the Study of Obesity: Consensus development conference on antipsychotic drugs and obesity and diabetes. Diabetes Care. 2004, 27:596-601. 10.2337/diacare.27.2.596

43. Glover G, Bernard S, Branford D, Holland A, Strydom A: Use of medication for challenging behaviour in people with intellectual disability. Br J Psychiatry. 2014, 205:6-7. 10.1192/bjp.bp.113.141267 